As this is not a controlled study it is not possible to prove that the number of hospital admissions from hypoglycaemia was reduced, but it is likely that some of 103 hypoglycaemic episodes in insulin dependent diabetic patients would have resulted in admission to hospital for treatment of hypoglycaemia if the patients had not received treatment by ambulance staff. Ten patients required intravenous glucose over nine months; this contrasts with 50 patients who required intravenous glucose in the same hospital over a seven month period in 1987 (A Collier, personal communication. $)^{3}$

The ambulance staff were very enthusiastic and the patients grateful. We believe that the administration of Lucozade and glucagon by ambulance personnel is safe, effective, and financially beneficial. We recommend its extension to other areas.
This practice has recently been extended to all of Scotland. We thank Dr K Little, Dr C Robertson, Beechams, Boehringer Mannheim, and Novo-Nordisk.

1 Diabetes Control and Complications Trial Research Group. Epidemiology of severe hypoglycaemia in the diabetes control and complications trial. Am f Med 1991;90:450-9.

2 Weston C, Stephens $M$. Hypoglycaemic attacks treated by ambulance personne with extended training. BMF 1990;300:908-9.

3 Collier A, Steedman DJ, Patrick AW, Matthews DM, Clarke BF, Little K. Comparison of intravenous glucagon and dextrose in treatment of severe Comparison of intravenous glucagon and dextrose in treatment of severe 1987:10:712-5.

4 Mulhauser I, Koch J, Berger M. Pharmacokinetics and bioavailability of injected glucagon: differences between intramuscular, subcutaneous and intravenous administration. Diabetes Care 1985;8 (suppl 1):39-42.

5 Yaxley L, Aldridge V, Almond J, Harradence F, Henry P, Heyburn PJ, et al. The treatment of severe hypoglycaemia with glucagon administered by ambulance personnel. Diabetic Med 1991;8 (suppl 1):71.

(Accepted 19 February 1992)
Queen Elizabeth Hospital, Edgbaston, Birmingham B15 2TH

I Greaves, registrar in nephrology and general medicine

A J Grant, house physician

D A Heath, honorary consultant physician

J Michael, consultant physician and nephrologist D Adu, consultant physician and nephrologist

Correspondence to: Dr Heath, department of medicine.

BMF 1992;304:1284

\section{Hypercalcaemia: changing causes over the past 10 years}

\author{
I Greaves, A J Grant, D A Heath, J Michael, \\ D Adu
}

In previous surveys in this hospital we have found malignancy to be the commonest cause of hypercalcaemia. In a retrospective survey hyperparathyroidism accounted for $13 \%$ of cases, $22 \%$ of cases being of unknown cause. ${ }^{1}$ In a subsequent, prospective study ${ }^{2}$ it was suggested that most of the cases of unexplained hypercalcaemia were due to primary hyperparathyroidism. In both surveys hypercalcaemia associated with renal failure was uncommon. We have recently completed a three month review of all hypercalcaemic patients in the same hospital and report here the results.

\section{Patients, methods, and results}

In the three months from May to July 1990, 181 hypercalcaemic patients with a corrected calcium concentration of greater than $2.7 \mathrm{mmol} / \mathrm{l}$ were identified from our biochemistry department computer database (correction factor: $0.02 \mathrm{mmol}$ calcium per 1 was added or subtracted/g albumin above or below $40 \mathrm{~g} / \mathrm{l}$ ). The notes of 162 of these patients were subsequently obtained; the remainder could not be identified. Half the cases of hypercalcaemia were in patients in chronic renal failure. Patients were dialysed against a calcium concentration of $1.75 \mathrm{mmol} / \mathrm{l}$. The comparison of the causes of hypercalcaemia in the three series is shown in the table.

In 1980 and 1981 we commented on the infrequent effective treatment of the hypercalcaemia of malignancy. In this new survey only five out of 30 patients received bisphosphonate, which is perhaps the current treatment of choice. ${ }^{3}$ Although retrospective assessment of

Causes of hypercalcaemia in the three series. Figures are numbers of patients

\begin{tabular}{lccc}
\hline & $\begin{array}{c}1990 \\
\text { Survey }\end{array}$ & $\begin{array}{c}\text { Retrospective } \\
\text { survey }\end{array}$ & $\begin{array}{c}\text { Prospective }^{1} \\
\text { survey }^{2}\end{array}$ \\
\hline Chronic renal failure & $81(50 \%)$ & $68(15 \%)$ & $6(3 \cdot 9 \%)$ \\
After renal transplantation & 21 & 219 & 89 \\
Malignancy & 35 & 59 & 53 \\
After liver transplantation & 5 & 102 & 6 \\
Primary hyperparathyroidism & 9 & 18 & 6 \\
Unexplained & 10 & 466 & 154 \\
Other & 1 & & \\
\hline Total & 162 & &
\end{tabular}

the need for treatment in malignant hypercalcaemia is difficult, we suspect that adequate treatment of this condition remains inconsistent. All the cases of primary hyperparathyroidism in our survey were routine admissions for surgery. In view of our previous experience it is likely that the unexplained hypercalcaemia was due to primary hyperparathyroidism.

\section{Comment}

The most surprising change over the past decade has been the enormous increase in hypercalcaemia associated with chronic renal failure, which occurred in 81 of the 162 patients in our survey. In 32 patients the calcium concentration was greater than $3.0 \mathrm{mmol} / \mathrm{l}$. Fifty three of the 81 patients were receiving calcium or vitamin $D$ supplementation, and in 44 cases the serum calcium concentration returned to normal after reducing or stopping vitamin $\mathrm{D}$ or calcium supplementation. Twenty patients had hypercalcaemia which settled without treatment. Only two of the 81 patients subsequently required parathyroidectomy. Twenty one patients in our study developed hypercalcaemia after receiving a renal transplant. Two of these patients became normocalcaemic after stopping calcium supplementation. The others did not require treatment.

In this study there were five cases of transient perioperative hypercalcaemia in liver transplant recipients, probably due to the large intraoperative infusion of calcium during the transplant operation.

The incidence of hypercalcaemia among renal patients seems, at least in part, to be due to calcium carbonate replacing aluminium hydroxide as a phosphate binder, with its concomitant advantages of the avoidance of aluminium toxicity and simultaneous calcium supplementation. The increased incidence of hypercalcaemia with calcium carbonate has been noted in previous studies. ${ }^{4}$ Although the incidence of symptomatic hypercalcaemia seemed low, we suggest that the treatment of the hypercalcaemia of chronic renal failure with calcium supplements should be monitored more carefully.

We were disappointed that the treatment of the hypercalcaemia of malignancy seemed not to have improved over 10 years despite marked improvement in the efficacy of therapeutic measures available.

1 Fisken RA, Heath DA, Bold AM. Hypercalcaemia-a hospital survey. $Q \mathcal{f} M e$ 1980;196:405-18

2 Fisken RA, Heath DA, Somers S, Bold AM. Hypercalcaemia in hospital patients. Lancet 1981; ;:202-6.

3 Heath DA. The treatment of hypercalcaemia of malignancy. Clin Endocrino 1991;34:155-7.

4 Malluche H, Faugere MC. Renal bone disease 1990: an unmet challenge for the nephrologist. Kidney Int 1990;39:193-211.

(Accepted 13 February 1992) 